\title{
An update on the diagnosis and management of the polyneuropathy of POEMS syndrome
}

\author{
Federica Cerri $^{1} \cdot$ Yuri Matteo Falzone ${ }^{1} \cdot$ Nilo Riva $^{1} \cdot$ Angelo Quattrini $^{1}$
}

Received: 5 May 2018 / Revised: 10 September 2018 / Accepted: 17 September 2018 / Published online: 27 September 2018

(c) The Author(s) 2019

\begin{abstract}
POEMS syndrome is a rare, chronic, disabling paraneoplastic disorder characterized by peripheral neuropathy, organomegaly, endocrinopathy, monoclonal plasma cells disorder and skin changes. Diagnosis relies on the fulfillment of a set of clinical criteria of which polyneuropathy and a monoclonal plasma cell dyscrasia are early and essential features. Treatment may be either local or systemic and is aimed at the monoclonal plasma cell disorder. Our knowledge of the pathogenesis underlying the POEMS syndrome has advanced greatly over the past years, favoring an important progression in the recognition and management of this disorder. Here, we discuss the recent literature that has advanced our knowledge of the pathogenesis and clinical management of the polyneuropathy in POEMS syndrome.
\end{abstract}

Keywords Vascular endothelial growth factor · Monoclonal gammopathy $\cdot$ CIDP $\cdot$ Nerve biopsy

\section{Introduction}

POEMS (polyneuropathy, organomegaly, endocrinopathy, M-protein, and skin changes) syndrome is a rare multisystemic paraneoplastic disorder associated with osteosclerotic myeloma and increased serum and plasma levels of vascular endothelial growth factor (VEGF) [1-7]. Although an estimated median survival of 14 years has been reported [8], the presence and progression of several clinical features affecting the respiratory and nervous systems, among others, are potentially fatal if left untreated [8]. The diagnosis of POEMS syndrome relies primarily on the fulfillment of major and minor criteria [8, 9]. However, the peripheral neuropathy is almost always a constant feature [10-14]. Indeed, the identification of a chronic progressive, distal, sensorimotor polyneuropathy, along with a monoclonal plasma cell dyscrasia, is essential to the diagnosis of POEMS syndrome.

Nilo Riva

riva.nilo@hsr.it

1 Neuropathology Unit, Division of Neuroscience and Department of Neurology, Institute of Experimental Neurology, San Raffaele Scientific Institute, Via Olgettina 48, 20132 Milan, Italy

\section{Proposed disease mechanisms}

Significant advances have been made in our understanding of the pathogenesis of POEMS syndrome, although a complete understanding of the underlying mechanisms has not yet been achieved. Current evidence supports the notion that at least some of its clinical findings, including peripheral neuropathy, are attributable to an increase in inflammatory cytokine levels rather than clonal plasma cells invasion [15].

VEGF is considered, together with other pro-inflammatory cytokines including tumor necrosis factor-alfa (TNF$\alpha$ ), interleukin-6 (IL-6) and interleukin-12 (IL-12), to be a relevant element in the pathogenesis of the disease [7, 16-21]. VEGF is a multifunctional cytokine, physiologically produced by osteoblasts and bone marrow-derived cells, including plasma cells [22-25]. It is pivotal in the regulation of angiogenesis and microvascular permeability by targeting different endothelial cell receptors [26]. Several upstream factors modulate VEGF production, such as the hypoxia-inducible transcription factor-1 (HIF-1), which is highly expressed in response to hypoxic conditions [20, 27]. Increased serum and plasma levels have been observed in the majority of cases and, therefore, considered a major criteria for the diagnosis of POEMS syndrome [4-7, 20, 21]. In addition, current evidence supports its value in the assessment of disease activity and treatment response [28-31]. The search of the origin of VEGF overproduction has led to 
controversial results. A recent study found higher levels of VEGF mRNA expression in the bone marrow plasma cells compared with CD138 negative cells [25]. Furthermore, polyclonal and monoclonal plasma cells showed comparable intracellular levels of VEGF, whereas monoclonal plasma cells exhibited higher levels of intracellular IL-6 expression [25], which is a known inducer of VEGF expression and secretion [5]. As mentioned previously, other inflammatory cytokines could be involved, since TNF- $\alpha$ and IL- 6 were reported to be upregulated in the blood/serum/plasma of POEMS syndrome patients, whereas IL-12 showed significant correlation with disease activity and progression [16, 19, 32, 33].

Lenalidomide, a promising therapy for POEMS syndrome, appears to be effective particularly on oedema and peripheral neuropathy, probably due to its anti-VEGF effect [34-36]. In contrast, bevacizumab, an anti-VEGF antibody, gave ambiguous results with several reports of patients getting much worse after therapy [37-39]. This failure could be due to persistent high VEGF serum levels followed by a rapid decrease, leading first to endothelial cells hypertrophy and second to massive apoptosis inducing a capillary leak syndrome [40]. Alternatively, other angiogenic factors may play an important role in POEMS syndrome [41], justifying the limited clinical efficacy obtained by inhibition of VEGF alone. These controversial findings suggest that the interplay of several cytokines involved in angiogenesis and microvascular permeability, besides VEGF, might be significant in the pathogenesis of POEMS syndrome, at least by explaining some of its clinical features such as extra-vascular volume overload (ascites, pleural effusion and oedema), skin angioma, papilloedema and presumably peripheral neuropathy $[7,15,17,20]$. Indeed, it is now accepted that VEGF is probably not the pathogenic initiating factor but a downstream mediator of a paraneoplastic syndrome.

\section{Multisystemic features and diagnosis of POEMS syndrome}

POEMS is a rare syndrome with a broad spectrum of clinical presentations and laboratory features. In recent years, revised diagnostic criteria have been proposed and adapted considering the progress made in understanding this syndrome [8, 9]. The diagnosis of POEMS syndrome is confirmed when both the polyneuropathy and monoclonal gammopathy are present in association with one of the other three major criteria (Castleman disease, sclerotic bone lesions and increased levels of VEGF), and one of the six minor criteria (organomegaly, endocrinopathy, extravascular volume overload, skin changes, papilloedema, thrombocytosis/polycythemia).
Osteosclerotic lesions occur in approximately $95 \%$ of patients [42]. Computed tomography (CT) scans can show both densely sclerotic or lytic lesions with a sclerotic rim; mixed lesions with soap-bubble appearance have also been observed. Lesions are usually multiple and small in size, revealing avid FDG uptake as they enlarge [42]. Endocrinopathy occurs in approximately $84 \%$ of patients, with a high incidence of hypogonadism and hypopituitarism followed by thyroid abnormalities and adrenal insufficiency. As thyroid disease and diabetes mellitus are common in the general population, and the latter may be present in both patients with POEMS and chronic inflammatory demyelinating polyradiculoneuropathy (CIDP), they should not be considered alone as diagnostic criteria for POEMS syndrome. In such cases, a combination of endocrine abnormalities may be more reliable for the fulfillment of these criteria. Typically, organomegaly affects the liver, spleen, and lymph nodes, which can be easily detected on a CT scan. The skin changes are heterogenous, including hyperpigmentation, hypertrichosis, hemangioma, acrocyanosis, flushing, white nails and thickening [43, 44]. In two POEMS patient cohorts, papilloedema occurred in approximately $50 \%$ of cases during a 10 years follow-up period [45]. In one of these studies, the presence of papilloedema was identified as an independent adverse factor for overall survival [46]. Ischemic stroke is an uncommon but recognised feature reported in approximately $10 \%$ of POEMS patients [47, 48]. It has rarely been described as a first clinical manifestation, occurring approximately 23 months after symptoms onset on average [49]. Indeed, a thrombotic diathesis is present in POEMS syndrome, as witnessed by the presence of thrombocytosis, seen in approximately $55 \%$ of patients, and bone marrow plasmacytosis, leading to a higher risk of ischemic stroke [47]. POEMS-associated strokes tend to involve largely watershed zones, and only on a few cases is it due to cerebral largevessel vasculitis. Extravascular volume overload generally manifests as peripheral oedema; ascites, pleural and pericardial effusion, pulmonary hypertension, renal dysfunction or cardiac insufficiency and may appear in advanced stages of the disease and is associated with a significantly shorter overall survival $[8,42]$.

Specific laboratory and recommended strategies for investigations are required to achieve the correct diagnosis and to guide adequate treatment in patients with POEMS syndrome. A thorough clinical assessment, including laboratory tests, neurophysiological and imaging studies, may be required to distinguish POEMS syndrome from other plasma cell dyscrasias and Castleman disease (CD). These tests include serum and urine protein electrophoresis and immunofixation, CT scans documenting osteoscleroic lesions, lymphadenopathy, organomegaly, ascites, pleural effusions, and oedema. Bone marrow aspirate and biopsy (test for kappa/lambda by immunohistochemistry) along with a 
serum and/or plasma VEGF level should be performed in case of suspected POEMS syndrome.

\section{Neuropathy in POEMS and mimic syndromes}

The early diagnosis of POEMS syndrome is critical, as treatment options for the disease in more advanced stages are frequently unsuccessful, despite appropriate therapy being applied. Delays in diagnosis are common and this has been reported to be higher than 13 months from symptoms onset in many cases [8]. This is due to the challenges in distinguishing POEMS syndrome at the onset from acquired chronic CIDP [14, 50-52]. Furthermore, POEMS syndrome should be distinguished from other neuropathies associated with monoclonal gammopathies such as monoclonal gammopathy of undetermined significance (MGUS) [14, 53, 54]. Although B-cell disorders are usually non-malignant, peripheral neuropathy also occurs with multiple myeloma, Waldenström's macroglobulinemia (WM), lymphoma, primary amyloidosis (AL), and lymphocytic leukemia $[55,56]$. Correct diagnosis of the above polyneuropathies is essential, as different disorders respond to different treatments [57, 58].

Peripheral neuropathy is frequently the presenting clinical feature, and it is commonly described as a progressive ascending, symmetric sensorimotor demyelinating polyneuropathy, sometimes evolving into polyradiculoneuropathy. Typically, patients show a high stepping gait. Prominent pain in the legs is usually reported in patients with POEMS, compared with patients with CIDP [59]. With the progression of the disorder, severe distal weakness at both lower and upper limbs ensues [8,14]. Although damage in both POEMS and CIDP is primarily demyelinating, neurophysiological studies in patients with POEMS show a higher degree of lengthdependent axonal loss, especially in the lower limbs, as evidenced by reduced amplitudes of compound muscle action potentials and more fibrillation potentials compared with CIDP [60, 61]. Furthermore, a more prominent slowing of nerve conduction in the intermediate than in the distal nerve segments has been reported, while demyelination in CIDP shows multifocal pattern involving both distal and intermediate segments [62]. Conduction blocks and temporal dispersion are less frequent in POEMS patients than CIDP. Cerebrospinal fluid examination and nerve imaging may show abnormalities but these are not specific for POEMS syndrome and can also be seen in CIDP, such as elevated cerebrospinal fluid protein levels and increased enhancement and enlargement of nerve roots [63]. Diabetes or glucose intolerance have been associated with both conditions.

The presence of a $\lambda$-type IgA or IgG monoclonal gammopathy is mandatory for the diagnosis of the POEMS syndrome. In MGUS-associated neuropathy the paraprotein is more commonly IgM [64-67], and the associated neuropathies are heterogenous, showing demyelinating, axonal, or axonal/demyelinating types [65-67]. In about half the patients with an IgM M-protein, the monoclonal protein reacts with myelin-associated glycoprotein (anti-MAG antibodies) [68-70], leading to a distal acquired demyelinating neuropathy (DADS). Patients with anti-MAG antibodies typically present with a chronic and slowly progressive, distal, symmetric, predominantly sensory demyelinating polyneuropathy, which begins with numbness and paresthesia in feet or hands and slowly progresses [69-71]. A deep sensory involvement is present, characterized by ataxia, loss of joint position, Romberg's sign and postural tremor in the upper limbs. However, multisystemic involvement is not observed in DADS and the disease is usually limited to the distal segments of the limbs. Besides DADS, an IgM isotype is also associated with WM, a malignant lymphoproliferative disease characterized by the clonal expansion of B-cells [72]. Although WM may share neuropathy and papilloedema with POEMS syndrome [73], a bone marrow biopsy is effective in distinguishing the two disorders [72, 74]. Neuropathies associated with IgG and IgA gammopathies are less common than neuropathies associated with IgM and are even more heterogeneous $[64,75]$. Patients affected by $\operatorname{IgG}$ and IgA gammopathies present with features of demyelinating, axonal, or mixed neuropathies.

$\mathrm{CD}$ is a rare lymphoproliferative disorder, characterized by enlarged lymph nodes, and occurs in approximately 11-30\% patients with POEMS syndrome [76]. CD can be classified according to whether the lymphadenopathy is unicentric or multicentric. Peripheral neuropathy is present in approximately $25 \%$ of patients with multicentric CD [14, 77, 78]. Unlike POEMS syndrome, CD patients present with a painless distal sensory demyelinating neuropathy, which is often mild in severity $[14,79]$. Although the pathogenesis of CD is unclear, VEGF, IL-6, and IL-1 may play an important role in the development of the disease. However, in contrast to POEMS, the predominantly elevated cytokine is IL-6, and not VEGF [14].

$\mathrm{AL}$ is a multisystemic disease characterized by widespread amyloid deposition, and diagnosis implies the presence of plasma cell dyscrasia [80], commonly lambdarestricted monoclonal plasma cells. Peripheral neuropathy is a common manifestation of $\mathrm{AL}$, with distal sensory symptoms, including painful dysesthesia, loss of light touch and temperature sensation, and marked autonomic involvement being the main clinical feature $[81,82]$. Distal symmetric weakness develops during the progression of AL. Patients with AL have electrophysiological features consistent with an axonal sensorimotor polyneuropathy, frequently associated with an autonomic neuropathy and carpal tunnel syndrome [83]. The diagnosis relies on the demonstration of amyloid deposits in tissue obtained from involved organs 
[82]. Bone marrow findings and the plasma or serum VEGF level are fundamental to distinguish POEMS syndrome from AL $[9,29]$.

\section{Pathological studies}

Sural nerve biopsy is rarely necessary to make the diagnosis of POEMS syndrome. However, nerve biopsy could be a useful tool in distinguishing POEMS syndrome from AL. In addition, pathological studies can contribute significantly to understanding the pathogenic mechanisms of nerve damage in POEMS syndrome [7, 20, 84].

Nerve biopsy in POEMS syndrome reveals major signs of demyelination with uncompacted myelin on electron microscopy in the absence of macrophage-associated demyelination [84-87], as observed in CIDP [88]. However, in our experience, nerve pathology in POEMS syndrome may also show predominant axonal damage characterized by loss of myelinated nerve fibers and the presence of myelin ovoids (Fig. 1), indicating acute axonal degeneration [20]. In addition, ultrastructural analysis of POEMS nerves has revealed endothelial cytoplasmic enlargement, opening of the tight junctions between endothelial cells, and presence of many pinocytic vesicles adjacent to the cell membranes (Fig. 1), suggesting an alteration in permeability of endoneurial vessels. Furthermore, the vascular damage correlated with the VEGF serum levels in patients. Thus, we propose that the mechanism underlying the peripheral neuropathy in POEMS syndrome is due to endothelial injury, indirectly or directly caused by an abnormal activation of endothelial cells by VEGF, which is overexpressed in the nerves of patients with POEMS syndrome, thereby inducing microvascular changes and impaired vascular permeability [7, 17, 20, 89]. These alterations lead to a secondary ischemic microangiopathy and chronic axonal damage of nerve fibers through alteration of the blood-nerve barrier [20]. Finally, the disruption of vascular and metabolic dynamics in the nerve leads to a perpetuating hypoxic state, where secondary increases in local VEGF occurs due to induced HIF-1a expression, fueling a positive destructive feedback whereby damage progresses relentlessly. Similarly, vessel structural derangement was also reported in skin capillaries [90].

Pathological evidence indicates that CIDP is caused by an inflammatory demyelination of spinal roots and peripheral nerves. Macrophages play a fundamental role in CIDP. The pathological hallmark of CIDP is macrophage-mediated segmental demyelination [88]. Nerve biopsies showed endoneurial edema and endoneurial perivascular infiltrates composed of macrophages and $\mathrm{T}$ lymphocytes [91, 92].
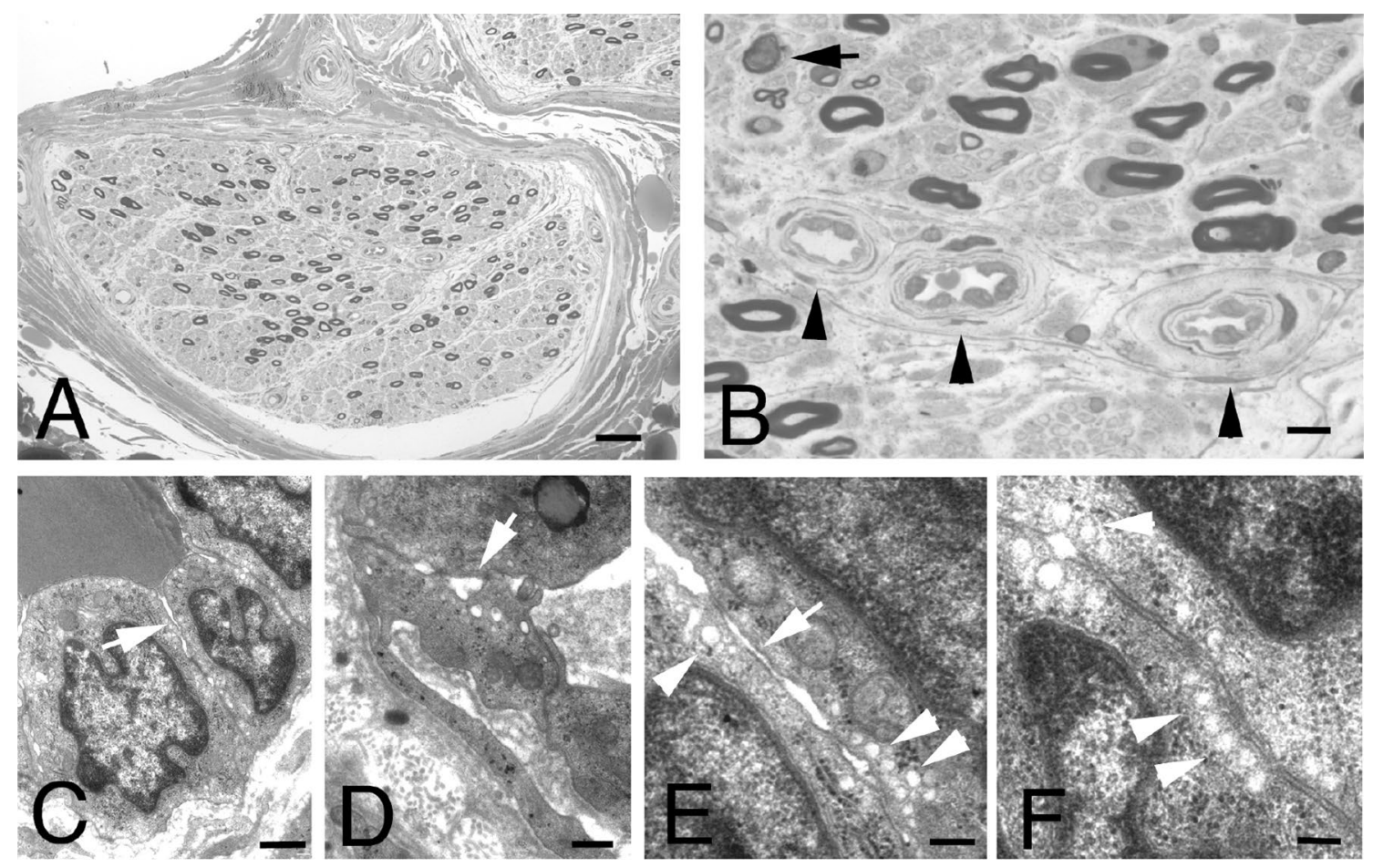

Fig. 1 Transverse semi thin sections of a sural nerve from a patient with POEMS syndrome showing diffuse reduction of the myelinated nerve fibers (a), axonal degeneration (b, arrow) and thickening of the vessel walls (b, arrowhead) due to basal lamina and cellular prolifera- tion. Electron micrographs showing endothelial cytoplasmic enlargement (c) and gap between endothelial cells (c-e, arrows). Many pinocytic vesicles adjacent to the cell membranes are present (e and $\mathbf{f}$, arrowhead). Scale bars: a: $40 \mu \mathrm{m} ; \mathbf{b}: 10 \mu \mathrm{m}$; c: $2 \mu \mathrm{m}$; d-f: $500 \mathrm{~nm}$ 
Inflammatory lymphocytes have been observed in the perineurium, whereas in POEMS inflammatory cells are scarce and localized perivascularly in the epineurium when present. In CIDP, progression of the disorder, associated with repeated demyelination and remyelination processes, results in onion bulb formation and axonal degeneration [93]. In addition, the pattern of damage in CIDP, including the fiber loss, follows a multifocal rather than diffuse pattern (Fig. 2) [94, 95], and this represents an important factor in distinguishing CIDP from other demyelinating polyneuropathies such as that seen in the POEMS syndrome [95].

Pathological studies in neuropathy with anti-MAG antibodies reveals demyelination (Fig. 2) in association with widening of myelin lamellae on electron microscopic examination [96] along with deposits of IgM and complement on myelin sheaths as demonstrated by direct immunohistochemistry (Fig. 2) [97, 98]. Immunocytochemical studies using anti-MAG antibodies from these patients has revealed that the antibodies were bound to the myelin. In nerve from patients with WM, pathological findings are similar to those seen in the neuropathy associated with anti-MAG [99]. However, in many patients with WM, axonal damage is prevalent due to a different mechanism of nerve damage, including vasculitic neuropathy, amyloid light chain deposition and tumoral infiltration of the nerve. Thus, nerve biopsy should be considered in patients showing a rapidly evolving course associated with pain and weight loss in WM. Neuropathies associated with IgG and IgA gammopathies are less common and present with features of a demyelinating, axonal, or mixed neuropathy.

The diagnosis of amyloid neuropathy depends on the demonstration of amyloid deposits in nerve biopsies [82]. Congo red staining can show amyloid deposits in the epineurium, perineurium or endoneurium (Fig. 2). In the endoneurium, amyloid can be observed focally in the vessel wall or with a large diffuse distribution in the endoneurial interstitial compartment. In our experience, in AL, amyloid deposits are prominent in and around vessel walls, while more
Fig. 2 Representative photomicrographs illustrating the nerve biopsy from patients with CIDP (a-c), anti-MAG (d-f) and amyloid neuropathy (AL) (g-i). In CIDP nerves, different degrees of large myelinated fibers loss between fascicles is evident ( $\mathbf{a}$ and $\mathbf{b}$ ); one fascicle has greater myelinated fibers loss (b), showing remyelination and multiple large onion bulbs (c, arrows). Demyelination and onion bulb formation in anti-MAG neuropathy (d and e, arrows); direct immunohistochemistry shows localization of IgM to the myelin sheath (f, arrows). Nerve biopsy of patient with $\mathrm{AL}$ shows severe reduction of myelinated nerve fibers and diffuse amyloid deposits in the endoneurium (g, asterisk) and in perivascular space (h, asterisk); histological slides stained with Congo red under under fluorescent microscopy showing scattered amyloid deposits in the endoneurium (i, arrows) and perivascular region (i, arrowhead). Scale bars: $\mathbf{a}$ and b: $60 \mu \mathrm{m} ; \mathbf{c}: 10 \mu \mathrm{m}$; d-f: $5 \mu \mathrm{m}$; $\mathbf{g}$ and $\mathbf{h}: 20 \mu \mathrm{m} ; \mathbf{i}: 40 \mu \mathrm{m}$
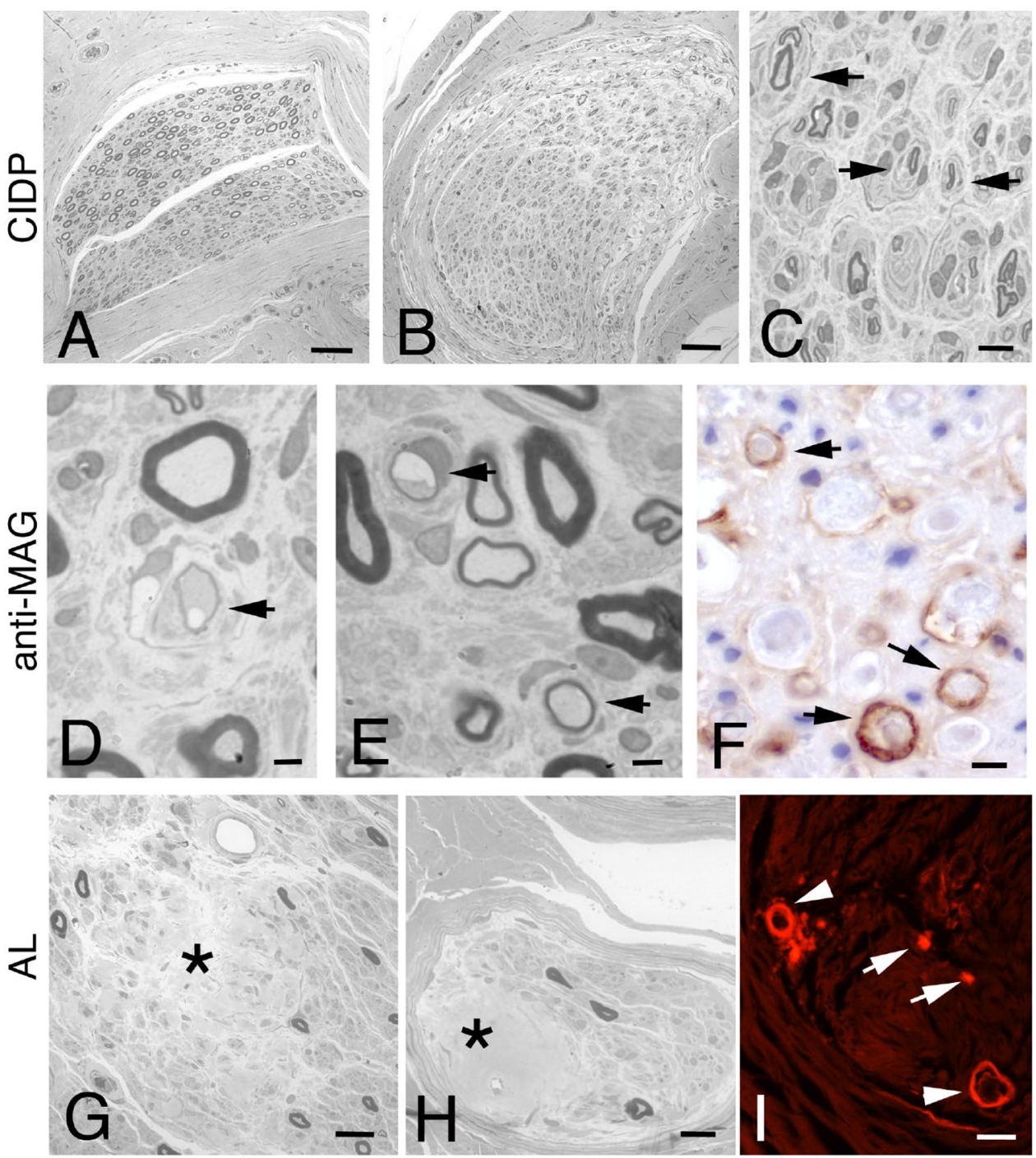
diffuse deposits in the endoneurium are present in hereditary amyloid neuropathies. In AL, the fundamental process is axonal degeneration. Although in early stages of the disease a selective loss of unmyelinated and small myelinated fibers is usually present, all fibers become severely affected with the progression of the disorder (Fig. 2).

\section{Treatment and clinical management}

An early and prompt diagnosis is fundamental to provide the best therapeutic intervention and follow-up recommendations. A multidisciplinary approach is essential for patients with POEMS syndrome and requires a core team of healthcare providers including a hematologist, neurologist, neurophysiologist and physiotherapist.

Treatment of POEMS syndrome is directed at the underlying monoclonal plasma cell disorder and depends on the extent of the disease and bone marrow involvement. In patients with two or fewer plasmacytoma lesions, radiotherapy is the first-line therapy. Patients with generalised disease, characterized by diffuse sclerotic lesions or disseminated bone marrow involvement, should be treated with systemic therapy $[9,40]$. Notably, plasmapheresis and intravenous immunoglobulin used in immune-mediated neuropathies seem unsuccessful [100]. High-dose chemotherapy-conditioned autologous stem cell transplantation is the current gold standard treatment for POEMS syndrome, showing good hematological control, neurological response, with improvement of the neuropathy, and good survival [101-104]. However, patients in advanced stage of disease cannot undergo autologous stem cell transplantation.

Potential new therapeutic approaches involve targeting key factors in the pathogenesis of POEMS, including VEGF, IL-6, IL-12 and TNF [40]. Thalidomide and lenalidomide (a derivative of thalidomide) are candidates to treat patients at high risk for transplantation because of their effectiveness against plasma cell proliferation, anti-VEGF and anticytokines effect [105]. Although thalidomide can strongly inhibit VEGF production, it can induce a toxic neuropathy and requires careful monitoring. Lenalidomide has a much lower risk of a peripheral neuropathy and has been shown to be effective against neuropathy and edema, reducing the serum levels of VEGF [34-36]. Indeed, treatment with lenalidomide in POEMS showed an improvement of the neuropathy in $90 \%$ of patients.

Neurorehabilitation is essential in patients with sensory and motor impairment. Orthopedic shoes to prevent footdrop, ankle-foot orthotics and other supporting devices can be used in patients with a debilitating neuropathy to improve quality of life. Pain may be a dominant feature in patients with POEMS and of course should be treated pharmacologically with drugs such as gabapentin and tricyclic antidepressants.

\section{Conclusions}

In summary, important progress has been made in the diagnosis and management of POEMS syndrome since its first description. Measurement of VEGF levels in the serum and plasma may help to make a rapid diagnosis, which is essential for the treatment of patients before severe neurologic impairment ensues. Early diagnosis and therapy can prevent progression and irreversible secondary axonal degeneration. Advances in our understanding of the underlying pathology in POEMS syndrome has identified new targets for future therapeutic efforts, particularly VEGF. However, more research is needed to understand what causes the excess production of cytokines that leads to the multiple clinical manifestations, and whether genetic factors are implicated in POEMS syndrome.

\section{Compliance with ethical standards}

Conflicts of interest All authors declare that they have no conflict of interest.

Open Access This article is distributed under the terms of the Creative Commons Attribution 4.0 International License (http://creativeco mmons.org/licenses/by/4.0/), which permits unrestricted use, distribution, and reproduction in any medium, provided you give appropriate credit to the original author(s) and the source, provide a link to the Creative Commons license, and indicate if changes were made.

\section{References}

1. Bardwick PA, Zvaifler NJ, Gill GN, Newman D, Greenway GD, Resnick DL (1980) Plasma cell dyscrasia with polyneuropathy, organomegaly, endocrinopathy, M protein, and skin changes: the POEMS syndrome. Report on two cases and a review of the literature. Medicine 59:311-322. https://doi.org/10.1097/00005 792-198007000-00006

2. Miralles GD, O'Fallon JR, Talley NJ (1992) Plasma-cell dyscrasia with polyneuropathy. The spectrum of POEMS syndrome. N Engl J Med 327:1919-1923. https://doi.org/10.1056/NEJM1 99212313272705

3. Vidaković A, Simić P, Stojisavljević N, Elezović I, Triki R, Apostolski S (1992) Polyneuropathy with osteosclerotic myelomaPOEMS syndrome. A case report. J Neurol 239:49-52

4. Watanabe O, Arimura K, Kitajima I, Osame M, Maruyama I (1996) Greatly raised vascular endothelial growth factor (VEGF) in POEMS syndrome. Lancet 347:702. https://doi.org/10.1016/ S0140-6736(96)91261-1

5. Soubrier M, Dubost JJ, Serre AF, Ristori JM, Sauvezie B, Cathebras P, Piette JC, Chapman A, Authier FJ, Gherardi RK (1997) Growth factors in POEMS syndrome: evidence for a marked increase in circulating vascular endothelial growth 
factor. Arthritis Rheum 40(4):786-787. https://doi.org/10.1002/ art. 1780400430

6. Nobile-Orazio E, Terenghi F, Giannotta C, Gallia F, Nozza A (2009) Serum VEGF levels in POEMS syndrome and in immune-mediated neuropathies. Neurology 72(11):1024-1026. https://doi.org/10.1212/01.wnl.0000344569.13496.f

7. Watanabe O, Maruyama I, Arimura K, Kitajima I, Arimura H, Hanatani M, Matsuo K, Arisato T, Osame M. (1998) Overproduction of vascular endothelial growth factor/vascular permeability factor is causative in Crow-Fukase (POEMS) syndrome. Muscle Nerve 21:1390-1397. https:// doi.org/10.1002/(SICI)1097-4598(199811)21:11\%3C139 0::AID-MUS5\%3E3.0.CO;2-4

8. Dispenzieri A, Kyle RA, Lacy MQ, Rajkumar SV, Therneau TM, Larson DR, Greipp PR, Witzig TE, Basu R, Suarez GA, Fonseca R, Lust JA, Gertz MA (2003) POEMS syndrome: definitions and long- term outcome. Blood 101(7):2496-2506. https://doi. org/10.1182/blood-2002-07-2299

9. Dispenzieri A (2017) POEMS syndrome: 2017 Update on diagnosis, risk stratification, and management. Am J Hematol 92:814-829. https://doi.org/10.1002/ajh.24802

10. Nakanishi T, Sobue I, Toyokura Y, Nishitani H, Kuroiwa Y, Satoyoshi E, Tsubaki T, Igata A, Ozaki Y (1984) The crowfukase syndrome: a study of 102 cases in japan. Neurology 34(6):712-720

11. Kelly JJ, Kyle RA, Miles JM, Dyck PJ (1983) Osteosclerotic myeloma peripheral neuropathy. Neurology 33(2):202-210

12. Takatsuki K, Sanada I (1983) Plasma cell dyscrasia with polyneuropathy and endocrine disorder: clinical and laboratory features of 109 reported cases. Jpn J Clin Oncol 13(3):543-556

13. Soubrier MJ, Dubost JJ, Sauvezie BJM (1994) POEMS syndrome: a study of 25 cases and a review of the literature. Am J Med 97(6):543-553. https://doi.org/10.1016/00029343(94)90350-6

14. Mauermann ML (2018) The peripheral neuropathies of POEMS syndrome and castleman disease. Hematol Oncol Clin N Am 32(1):153-163. https://doi.org/10.1016/j.hoc.2017.09.012

15. Li J, Zhou DB (2013) New advances in the diagnosis and treatment of POEMS syndrome. Br J Haematol 161(3):303-315. https ://doi.org/10.1111/bjh.12236

16. Gherardi RK, Bélec L, Soubrier M, Malapert D, Zuber M, Viard JP, Intrator L, Degos JD, Authier FJ (1996) Overproduction of proinflammatory cytokines imbalanced by their antagonists in POEMS syndrome. Blood 87:1458-1465

17. Arimura K (1999) Increased vascular endothelial growth factor (VEGF) is causative in Crow-Fukase syndrome. Clin Neurol 39(1):84-85

18. Soubrier M, Sauron C, Souweine B, Larroche C, Wechsler B, Guillevin L, Piette JC, Rousset H, Deteix P (1999) Growth factors and proinflammatory cytokines in the renal involvement of POEMS syndrome. Am J Kidney Dis 34(4):633-638. https://doi. org/10.1016/S0272-6386(99)70386

19. Michizono K, Umehara F, Hashiguchi T, Arimura K, Matsuura E, Watanabe O, Fujimoto N, Okada Y, Osame M (2001) Circulating levels of MMP-1, $-2,-3,-9$, and TIMP-1 are increased in POEMS syndrome. Neurology 56:807-810. https://doi.org/10.1212/ WNL.56.6.807

20. Scarlato M, Previtali SC, Carpo M, Pareyson D, Briani C, Del Bo R, Nobile-Orazio E, Quattrini A, Comi GP (2005) Polyneuropathy in POEMS syndrome: Role of angiogenic factors in the pathogenesis. Brain 128(8):1911-1920. https://doi.org/10.1093/ brain/awh519

21. Dyck PJ, Engelstad J, Dispenzieri A (2006) Vascular endothelial growth factor and POEMS. Neurology 66:10-12. https://doi. org/10.1212/01.wnl.0000194614.56025.ec
22. Hashiguchi T, Arimura K, Matsumuro K, Otsuka R, Watanabe O, Jonosono M, Maruyama Y, Maruyama I, Osame M. (2000) Highly concentrated vascular endothelial growth factor in platelets in Crow-Fukase syndrome. Muscle Nerve 23(7):10511056. https://doi.org/10.1002/1097-4598(200007)23:7\%3C105 $1:: A I D-M U S 7 \% 3 E 3.0 . C O ; 2-V$

23. Nakano A, Mitsui T, Endo I, Takeda Y, Ozaki S, Matsumoto $\mathrm{T}$ (2001) Solitary plasmacytoma with VEGF overproduction: report of a patient with polyneuropathy. Neurology 56(6):818 819. https://doi.org/10.1212/WNL.56.6.818

24. Nakajima H, Ishida S, Furutama D, Sugino M, Kimura F, Yokote T, Baba I, Tsuji M, Hanafusa T (2007) Expression of vascular endothelial growth factor by plasma cells in the sclerotic bone lesion of a patient with POEMS syndrome. J Neurol 254(4):531533. https://doi.org/10.1007/s00415-006-0268-y

25. Wang C, Huang XF, Cai QQ, Cao XX, Cai H, Zhou D, Li J (2016) Remarkable expression of vascular endothelial growth factor in bone marrow plasma cells of patients with POEMS syndrome. Leuk Res 50:78-84. https://doi.org/10.1016/j.leukr es.2016.09.017

26. Olsson AK, Dimberg A, Kreuger J, Claesson-Welsh L (2006) VEGF receptor signalling: in control of vascular function. Nat Rev Mol Cell Biol 7:359-371. https://doi.org/10.1038/nrm1911

27. Pugh CW, Ratcliffe PJ (2003) Regulation of angiogenesis by hypoxia: role of the hif system. Nat Med 9(6):677-684. https:// doi.org/10.1038/nm0603-677

28. Koga H, Tokunaga Y, Hisamoto T, Sujaku K, Mitsuyama K, Matsuo K, Ueno T, Sata M (2002) Ratio of serum vascular endothelial growth factor to platelet count correlates with disease activity in a patient with POEMS syndrome. Eur J Intern Med 13(1):70-74. https://doi.org/10.1016/S0953-6205(01)00199-6

29. Briani C, Fabrizi GM, Ruggero S, Torre CD, Ferrarini M, Campagnolo M, Cavallaro T, Ferrari S, Scarlato M, Taioli F, Adami F (2011) Vascular endothelial growth factor helps differentiate neuropathies in rare plasma cell dyscrasias. Muscle Nerve 43(2):164-167. https://doi.org/10.1002/mus.21872

30. D'Souza A, Hayman SR, Buadi F, Mauermann M, Lacy MQ, Gertz MA, Kyle RA, Kumar S, Greipp PR, Lust JA, Russell SJ, Zeldenrust S, Dingli D, Witzig TE, Rajkumar SV, Dispenzieri A (2011) The utility of plasma vascular endothelial growth factor levels in the diagnosis and follow-up of patients with POEMS syndrome. Blood 118(17):4663-4665. https://doi.org/10.1182/ blood-2011-06-362392

31. Misawa S, Sato Y, Katayama K, Hanaoka H, Sawai S, Beppu M, Nomura F, Shibuya K, Sekiguchi Y, Iwai Y, Watanabe K, Amino H, Ohwada C, Takeuchi M, Sakaida E, Nakaseko C, S Kuwabara (2015) Vascular endothelial growth factor as a predictive marker for POEMS syndrome treatment response: retrospective cohort study. BMJ Open 11;5(11):e009157 https://doi.org/10.1136/ bmjopen-2015-009157

32. Kanai K, Sawai S, Sogawa K, Mori M, Misawa S, Shibuya K, Isose S, Fujimaki Y, Noto Y, Sekiguchi Y, Nasu S, Nakaseko C, Takano S, Yoshitomi H, Miyazaki M, Nomura F, Kuwabara S (2012) Markedly upregulated serum interleukin-12 as a novel biomarker in POEMS syndrome. Neurology 79(6):575-582. https://doi.org/10.1212/WNL.0b013e318263c42b

33. Gherardi RK, Belec L, Fromont G, Divine M, Malapert D, Gaulard P, Degos JD (1994) Elevated levels of interleukin-1 beta (IL-1 beta) and IL-6 in serum and increased production of IL-1 beta mRNA in lymph nodes of patients with polyneuropathy, organomegaly, endocrinopathy, M protein, and skin changes (POEMS) syndrome. Blood 83:2587-2593

34. Dispenzieri A, Klein CJ, Mauermann ML (2007) Lenalidomide therapy in a patient with POEMS syndrome. Blood 110(3):10751076. https://doi.org/10.1182/blood-2007-03-082354 
35. Royer B, Merlusca L, Abraham J, Musset L, Haroche J, Choquet S, Leleu X, Sebban C, Decaux O, Galicier L, Roussel M, Recher C, Banos A, Guichard I, Brisseau J, Godmer P, Hermine O, Deplanque G, Facon T, Asli B, Leblond V, Fermand J, Marolleau JP, Jaccard A (2013) Efficacy of lenalidomide in POEMS syndrome: a retrospective study of 20 patients. Am J Hematol 88:207-212. https://doi.org/10.1002/ajh.23374

36. Nozza A, Terenghi F, Gallia F, Adami F, Briani C, Merlini G, Gordano L, Santoro A, Nobile-Orazio E (2017) Lenalidomide and dexamethasone in patients with POEMS syndrome: results of a prospective, open label-trial. Br J Haematol 179(5):748-755. https://doi.org/10.1111/bjh.14966

37. Badros A, Porter N, Zimrin A (2005) Bevacizumab therapy for POEMS syndrome. Blood 106:1135. https://doi.org/10.1182/ blood-2005-03-0910

38. Ohwada C, Nakaseko C, Sakai S, Takeda Y, Abe D, Takeuchi M, Sakaida E, Masuda S, Shimizu N, Cho R, Nishimura M, Kanai K, Misawa S, Kuwabara S (2009) Successful combination treatment with bevacizumab, thalidomide and autologous PBSC for severe POEMS syndrome. Bone Marrow Transplant 43(9):739-740. https://doi.org/10.1038/bmt.2008.381

39. Kanai K, Kuwabara S, Misawa S, Hattori T (2007) Failure of treatment with anti-VEGF monoclonal antibody for long-standing POEMS syndrome. Intern Med 46:311-313. https://doi. org/10.2169/internalmedicine.46.6246

40. Jaccard A (2018) POEMS syndrome therapeutic options. Hematol Oncl Cli North Am 32(1):141-151. https://doi.org/10.1016/j. hoc.2017.09.011

41. Yamada Y, Sawai S, Misawa S, Kanai K, Shibuya K, Mori M, Moriya J, Sogawa K, Yamamoto H, Beppu M, Taniguchi J, Nakaseko C, Nomura F, Kuwabara S (2013) Multiple angiogenetic factors are upregulated in POEMS syndrome. Ann Hematol 92:245-248

42. Dispenzieri A, Kourelis T, Buadi F (2018) POEMS syndrome diagnosis and investigative work-up. Hematol Oncol Clin N Am 32:119-139. https://doi.org/10.1016/j.hoc.2017.09.010

43. Iwashita H, Ohnishi A, Asada M, Kanazawa Y, Kuroiwa Y (1977) Polyneuropathy, skin hyperpigmentation, edema, and hypertrichosis in localized osteosclerotic myeloma. Neurology 27(7):675-681

44. Chan JKC, Fletcher CDM, Hicklin GA, Rosai J (1990) Glomeruloid hemangioma: a distinctive cutaneous lesion of multicentric castleman's disease associated with POEMS syndrome. Am J Surg Pathol 14(11):1036-1046

45. Kaushik M, Pulido JS, Abreu R, Amselem L, Dispenzieri A (2011) Ocular findings in patients with polyneuropathy, organomegaly, endocrinopathy, monoclonal gammopathy, and skin changes syndrome. Ophthalmology 118(4):778-782. https://doi. org/10.1016/j.ophtha.2010.08.013

46. Cui R, Yu S, Huang X, Zhang J, Tian C, Pu C (2014) Papilloedema is an independent prognostic factor for POEMS syndrome. J Neurol 261(1):60-65

47. Dupont SA, Dispenzieri A, Mauermann ML, Rabinstein AA, Brown RD (2009) Cerebral infarction in POEMS syndrome: incidence, risk factors, and imaging characteristics. Neurology 73(16):1308-1312. https://doi.org/10.1212/WNL.0b013e3181 bd136b

48. Fu FW, Rao J, Zheng YY, Wang HL, Yang JG, Zheng GQ (2017) Ischemic stroke in patients with POEMS syndrome: a case report and comprehensive analysis of literature. Oncotarget 8(51):89406-89424. https://doi.org/10.18632/oncotarget.20131

49. Dacci P, Lessi F, Della Bella E, Morbini M, Briani C, Lauria G (2013) Ischemic stroke as clinical onset of POEMS syndrome. J Neurol 260:3178-3181. https://doi.org/10.1007/s0041 $5-013-7180-\mathrm{z}$
50. Nasu S, Misawa S, Sekiguchi Y, Shibuya K, Kanai K, Fujimaki Y, Ohmori S, Mitsuma S, Koga S, Kuwabara S (2012) Different neurological and physiological profiles in POEMS syndrome and chronic inflammatory demyelinating polyneuropathy. J Neurol Neurosurg Psychiatry 83(5):476-479. https://doi.org/10.1136/ jnnp-2011-301706

51. Naddaf E, Dispenzieri A, Mandrekar J, Mauermann ML (2015) Thrombocytosis distinguishes POEMS syndrome from chronic inflammatory demyelinating polyneuropathy. Muscle Nerve 52(4):658-659. https://doi.org/10.1002/mus.24768

52. Keddie S, D'Sa S, Folders D, Carr AS, Reilly MM, Lunn MPT (2018) POEMS neuropathy: optimizing diagnosis and management. Pract Neurol 001792. https://doi.org/10.1136/practneuro 1-2017-001792

53. Joint Task Force of the EFNS and the PNS (2010) European Federation of Neurological Societies/Peripheral Nerve Society Guideline on management of paraproteinemic demyelinating neuropathies. Report of a Joint Task Force of the European Federation of Neurological Societies and the Peripheral Nerve Society-first revision. J Peripher Nerv Syst 15:185-195. https ://doi.org/10.1111/j.1529-8027.2010.00278.x

54. Alkhawajah NM, Dunnigan SK, Bril V (2014) Comparison of monoclonal gammopathy of undetermined significance-associated neuropathy and chronic inflammatory demyelinating polyneuropathy patients. J Neurol 261:1485-1491. https://doi. org/10.1007/s00415-014-7357-0

55. Steck A (1998) Neurological manifestations of malignant and non-malignant dysglobulinaemias. J Neurol 245:634. https://doi. org/10.1007/s004150050259

56. Riva N, Bezzi G, Ponzoni M, Epis R, Previtali SC, Cerri F, Nemni R, Comi G, Quattrini A (2008) Lymphomatous neuropathy in cold agglutinin disease. Neurology 6 70(19):1715-1716. https://doi.org/10.1212/01.wnl.0000311387.62152.a2

57. Said G (2002) Chronic inflammatory demyelinative polyneuropathy. J Neurol 249:245. https://doi.org/10.1007/s004150200000

58. Amin RA, Robertson NP (2015) Diagnosis and treatment of chronic inflammatory demyelinating polyneuropathy. J Neurol 262:789. https://doi.org/10.1007/s00415-015-7667-

59. Koike H, Iijima M, Mori K, Yamamoto M, Hattori N, Watanabe H, Tanaka F, Doyu M, Sobue G (2008) Neuropathic pain correlates with myelinated fibre loss and cytokine profile in POEMS syndrome. J Neurol Neurosurg Psychiatry 79(10):1171-1179. https://doi.org/10.1136/jnnp.2007.135681

60. Molenaar D, Vermeulen M, de Haan R (2002) Comparison of electrodiagnostic criteria for demyelination in patients with chronic inflammatory demyelinating polyneuropathy (CIDP). J Neurol 249:400-403. https://doi.org/10.1007/s004150200029

61. Mauermann ML, Sorenson EJ, Dispenzieri A, Mandrekar J, Suarez GA, Dyck PJ, Dyck PJB (2012) Uniform demyelination and more severe axonal loss distinguish POEMS syndrome from CIDP. J Neurol Neurosurg Psychiatry 83(5):480-486. https://doi. org/10.1136/jnnp-2011-301472

62. Sung JY, Kuwabara S, Ogawara K, Kanai K, Hattori T (2002) Patterns of nerve conduction abnormalities in poems syndrome. Muscle Nerve 26(2):189-193. https://doi.org/10.1002/mus.10182

63. Kronlage M, Bäumer P, Pitarokoili K, Schwarz D, Schwehr V, Godel T, Heiland S, Gold R, Bendszus M, Yoon MS (2017) Large coverage MR neurography in CIDP: diagnostic accuracy and electrophysiological correlation. J Neurol 264:1434-1443. https://doi.org/10.1007/s00415-017-8543-7

64. Suarez GA, Kelly JJ (1993) Polyneuropathy associated with monoclonal gammopathy of undetermined significance: further evidence that IgM-MGUS neuropathies are different than IgGMGUS. Neurology 43:1304-1308 
65. Nobile-Orazio E, Manfredini E, Carpo M, Meucci N, Monaco S, Ferrari S, Bonetti B, Cavalletti G, Gemignani F, Durelli L (1994) Frequency and clinical correlates of anti-neural IgM antibodies in neuropathy associated with IgM monoclonal gammopathy. Ann Neurol 36(3):416-424. https://doi.org/10.1002/ana.41036 0313

66. Ellie E, Vital A, Steck A, Boiron JM, Vital C, Julien J (1996) Neuropathy associated with "benign" anti-myelin-associated glycoprotein IgM gammopathy: clinical, immunological, neurophysiological, pathological findings and response to treatment in 33 cases. J Neurol 243:34-43

67. Kyle RA, Therneau TM, Rajkumar SV, Larson DR, Plevak MF, Offord JR, Dispenzieri A, Katzmann JA, Melton LJ (2006) Prevalence of monoclonal gammopathy of undetermined significance. N Engl J Med 354(13):1362-1369. https://doi.org/10.1056/ NEJMoa054494

68. Latov N, Sherman WH, Nemni R, Galassi G, Shyong JS, Penn AS, Chess L, Olarte MR, Rowland LP, Osserman EF (1980) Plasma-cell dyscrasia and peripheral neuropathy with a monoclonal antibody to peripheral-nerve myelin. N Engl J Med 303:618621. https://doi.org/10.1056/NEJM198009113031105

69. Kaku DA, England JD, Sumner AJ (1994) Distal accentuation of conduction slowing in polyneuropathy associated with antibodies to myelin-associated glycoprotein and sulphated glucuronyl paragloboside. Brain 117(Pt 5):941-947

70. Nobile-Orazio E, Meucci N, Baldini L, Di Troia A, Scarlato G (2000) Long-term prognosis of neuropathy associated with antiMAG IgM M-proteins and its relationship to immune therapies. Brain 123(Pt 4):710-717

71. Radziwill AJ, Steck AJ, Renaud S, Fuhr P (2003) Distal motor latency and residual latency as sensitive markers of antiMAG polyneuropathy. J Neurol 250(8):962-966. https://doi. org/10.1007/s00415-003-1128-7

72. Dimopoulos MA, Panayiotidis P, Moulopoulos LA, Sfikakis P, Dalakas M (2000) Waldenström's macroglobulinemia: clinical features, complications, and management. J Clin Oncol 18:214226. https://doi.org/10.1200/JCO.2000.18.1.214

73. Pinna A, Dore S, Dore F, Salis A, Carta F (2003) Bilateral optic disc swelling as the presenting sign of Waldenström's macroglobulinaemia. Acta Ophthalmol Scand 81(4):413-415

74. D'Sa S, Kersten MJ, Castillo JJ, Dimopoulos M, Kastritis E, Laane E, Leblond V, Merlini G, Treon SP, Vos JM, Lunn MP (2017) Investigation and management of IgM and Waldenströmassociated peripheral neuropathies: recommendations from the IWWM-8 consensus panel. Br J Haematol 176:728-742. https ://doi.org/10.1111/bjh.14492

75. Magy L, Chassande B, Maisonobe T, Bouche P, Vallat JM, Leger JM (2003) Polyneuropathy associated with $\mathrm{IgG} / \mathrm{IgA}$ monoclonal gammopathy: a clinical and electrophysiological study of 15 cases. Eur J Neurol 10:677-685

76. Naddaf E, Dispenzieri A, Mandrekar J, Mauermann ML (2016) Clinical spectrum of Castleman disease-associated neuropathy. Neurology 87(23):2457-2462. https://doi.org/10.1212/ WNL.00000000000034

77. Hineman VL, Phyliky RL, Banks PM (1982) Angiofollicular lymph node hyperplasia and peripheral neuropathy: association with monoclonal gammopathy. Mayo Clin Proc 57(6):379-382

78. Donaghy M, Hall P, Gawler J, Gregson NA, Leibowitz S, Jitpimolmard S, King RH, Thomas PK (1989) Peripheral neuropathy associated with Castleman's disease. J Neurol Sci 89:253-267

79. Dispenzieri A, Armitage JO, Loe MJ, Geyer SM, Allred J, Camoriano JK, Menke DM, Weisenburger DD, Ristow K, Dogan A, Habermann TM (2012) The clinical spectrum of Castleman's disease. Am J Hematol 87(11):997-1002. https://doi.org/10.1002/ ajh. 23291
80. Duston MA, Skinner M, Anderson J, Cohen AS (1989) Peripheral neuropathy as an early marker of AL amyloidosis. Arch Intern Med 149:358-360

81. Kyle RA, Greipp PR (1983) Amyloidosis (AL). Clinical and laboratory features in 229 cases. Mayo Clin Proc 58:665-683

82. Gertz MA, Kyle RA (1989) Primary systemic amyloidosis: a diagnostic primer. Mayo Clin Proc 64:1505-1519

83. Kelly JJ, Kelly RA, O'Brien PC, Dyck PJ (1979) The natural history of peripheral neuropathy in primary systemic amyloidosis. Ann Neurol 6:1-7

84. Hashimoto R, Koike H, Takahashi M, Ohyama K, Kawagashira Y, Iijima M, Sobue G (2015) Uncompacted myelin lamellae and nodal ion channel disruption in POEMS syndrome. J Neuropathol Exp Neurol 74(12):1127-1136

85. Gherardi R, Vital A, Kopp N, Pellissier JF, Soubrier M, Clavelou P, Bellance R, Delisle MB, Ruchoux MM, Hauw JJ (1994) Uncompacted myelin lamellae in polyneuropathy, organomegaly, endocrinopathy, M-protein and skin changes syndrome - Ultrastructural study of peripheral nerve biopsy from 22 patients. Acta Neuropathol 87(3):302-307. https://doi.org/10.1007/BF002 96746

86. Adams D, Said G (1998) Ultrastructural characterisation of the $\mathrm{M}$ protein in nerve biopsy of patients with POEMS syndrome. $\mathrm{J}$ Neurol Neurosurg Psychiatry 64:809-812

87. Vital C, Vital A, Ferrer X, Viallard JF, Pellegrin JL, Bouillot S, Larrieu JM, Lequen L, Larrieu JL, Brechenmacher C, Petry KG, Lagueny A (2003) Crow-Fukase (POEMS) syndrome: a study of peripheral nerve biopsy in five new cases. J Peripher Nerv Syst 8:136-144. https://doi.org/10.1046/j.1529-8027.2003.03019.x

88. Sommer C, Koch S, Lammens M, Gabreels-Festen A, Stoll G, Toyka KV (2005) Macrophage clustering as a diagnostic marker in sural nerve biopsies of patients with CIDP. Neurology 65:1924-1929. https://doi.org/10.1212/01.wnl.0000188879 $.19900 . b 7$

89. Saida K, Kawakami H, Ohta M, Iwamura K (1997) Coagulation and vascular abnormalities in Crow-Fukase syndrome. Muscle Nerve 20:486-492

90. Santoro L, Manganelli F, Bruno R, Nolano M, Provitera V, Barbieri F (2006) Sural nerve and epidermal vascular abnormalities in a case of POEMS syndrome. Eur J Neurol 13(1):99-102. https ://doi.org/10.1111/j.1468-1331.2006.01117.x

91. Winer J, Hughes S, Cooper J, Ben-Smith A, Savage C (2002) Gamma delta $\mathrm{T}$ cells infiltrating sensory nerve biopsies from patients with inflammatory neuropathy. J Neurol 249:616-621. https://doi.org/10.1007/s004150200072

92. Quattrini A, Previtali SC, Kieseier BC, Kiefer R, Comi G, Hartung HP (2003) Autoimmunity in the peripheral nervous system. Cri RewNeurobiol 15(1):1-39

93. Vital C, Vital A, Lagueny A, Ferrer X, Fontan D, Barat M, Gbikpi-Benissan G, Orgogozo JM, Henry P, Brechenmacher C, Bredin A, Desbordes P, Ribière-Bachelier C, Latinville D, Julien J, Pétry KG (2000) Chronic inflammatory demyelinating polyneuropathy: immunopathological and ultrastructural study of peripheral nerve biopsy in 42 cases. Ultrastruct Pathol 24:363-369

94. Rizzuto N. Morbin M, Cavallaro T, Ferrari S, Fallahi M, Galiazzo Rizzuto S (1998) Focal lesions area feature of chronic inflammatory demyelinating polyneuropathy (CIDP). Acta Neuropathol 96:603-609

95. Piccione EA, Engelstad J, Dyck PJ, Mauermann ML, Dispenzieri A, Dyck PJ (2016) Nerve pathologic features differentiate POEMS syndrome from CIDP. Acta Neuropathol Commun 31(1):116. https://doi.org/10.1186/s40478-016-0389-1

96. Vital A, Vital C, Julien J, Baquey A, Steck AJ (1989) Polyneuropathy associated with IgM monoclonal gammopathy. 
Immunological and pathological study in 31 patients. Acta Neuropathol 79:160-167

97. Takatsu M, Hays AP, Latov N, Abrams GM, Nemni R, Sherman WH, Nobile-Orazio E, Saito T, Freddo L (1985) Immunofluorescence study of patients with neuropathy and IgM M proteins. Ann Neurol 18:173-181. https://doi.org/10.1002/ana.410180203

98. Hays AP, Lee SS, Latov N (1988) Immune reactive C3d on the surface of myelin sheaths in neuropathy. J Neuroimmunol 18:231-244

99. Vital C, Vital A, Deminiere C, Julien J, Lagueny A, Steck AJ (1997) Myelin modifications in 8 cases of peripheral neuropathy with Waldenström's macroglobulinemia and anti-MAG activity. Ultrastruct Pathol 21:509-516

100. Huang CC, Chu CC (1996) Poor response to intravenous immunoglobulin therapy in patients with Castleman's disease and the POEMS syndrome. J Neurol 243:726-727

101. Kuwabara S, Misawa S, Kanai K, Suzuki Y, Kikkawa Y, Sawai S, Hattori T, Nishimura M, Nakaseko C (2008) Neurologic improvement after peripheral blood stem cell transplantation in POEMS syndrome. Neurology 71:1691-1695. https://doi. org/10.1212/01.wnl.0000323811.42080.a4

102. D'Souza A, Lacy M, Gertz M, Kumar S, Buadi F, Hayman S, Dingli D, Zeldenrust S, Kyle R, Ansell S, Inwards D, Johnston P, Micallef I, Porrata L, Litzow M, Gastineau D, Hogan
W, Dispenzieri A (2012) Long-term outcomes after autologous stem cell transplantation for patients with POEMS syndrome (osteosclerotic myeloma): a single-center experience. Blood 120:56-62. https://doi.org/10.1182/blood-2012-04-423178

103. Karam C, Klein CJ, Dispenzieri A, Dyck PJB, Mandrekar J, D’Souza A, Mauermann ML (2015) Polyneuropathy improvement following autologous stem cell transplantation for POEMS syndrome. Neurology 84(19):1981-1987. https://doi. org/10.1212/WNL.0000000000001565

104. Cook G, Iacobelli S, van Biezen A, Ziagkos D, LeBlond V, Abraham J, McQuaker G, Schoenland S, Rambaldi A, Halaburda K, Rovira M, Sica S, Byrne J, Sanz RG, Nagler A, van de Donk NW, Sinisalo M, Cook M, Kröger N, De Witte T, Morris C, Garderet L (2017) High-dose therapy and autologous stem cell transplantation in patients with POEMS syndrome: a retrospective study of the Plasma Cell Disorder sub-committee of the Chronic Malignancy Working Party of the European Society for Blood \& Marrow Transplantation. Haematologica 102:160-167. https ://doi.org/10.3324/haematol.2016.148460

105. Zagouri F, Kastritis E, Gavriatopoulou M, Sergentanis TN, Psaltopoulou T, Terpos E, Dimopoulos MA (2014) Lenalidomide in patients with POEMS syndrome: a systematic review and pooled analysis. Leuk Lymphoma 55:2018-2023. https://doi. org/10.3109/10428194.2013.869329 